\title{
A SPORTS MEDICINE CLINIC IN THE COMMUNITY
}

J. DAVISON and M. P. RYAN

Department of Community Medicine, Bangour General Hospital, Broxburn, West Lothian

\section{ABSTRACT}

We report the attempt to set up a mini sports medicine clinic in a health centre resourced by a Department of Community Medicine. The type of problems seen are similar to those reported by other clinics. On the results of this pilot project, we believe it would be possible to establish similar clinics in health centres elsewhere in the United Kingdom. The National Health Service resources required are minimal, but the benefits to local communities are considerable.

Key words: Mini sports medicine clinic, Dept. of Community Medicine, Health centre

\section{INTRODUCTION}

In spite of the increase in the number of people, both young and old, participating in sport, the development of facilities to provide treatment and medical advice for those injured as a result of sporting activities has been slow. Sperryn and Williams (1975) argued the case for sports injuries clinics and the same arguments apply today. Accident and Emergency Departments are likely to see the majority of acute injuries initially, but the casualty officers may not treat these problems appropriately nor have they necessarily a particular interest in this field (Burke et al, 1983). There have been reports of sports medicine clinics based in hospitals, general practice and special clinics separate from both (Crompton and Tubbs, 1977; Brodie, 1983). We report the results of a pilot study to establish a mini sports medicine clinic in a health centre using the medical and physiotherapy resources of a Department of Community Medicine. The clinic is based in the community using one of the four health centres in the new town of Livingston in Scotland.

Since there were no specific provisions for the diagnosis and treatment of sports injuries locally it seemed appropriate to make use of community medicine resources to establish a sports medicine clinic. The clinic was set up in 1981, following discussion with the health centre general practitioners, community medicine specialists, the physiotherapy department and the Division of General Practice. It was decided to hold the clinic in one of the health centres on a Monday evening for one hour. The clinic was arranged in such a way that treatment was not given on the same evening, but either the next day or as soon as convenient during normal working hours.

The five-year experimental period was used to assess the viability of maintaining such a clinic locally and to give a precise record of the use of hospital resources such as specialist referral, $X$-rays and investigations directly attributable to sports related problems.

The health centre in which the clinic is held, has a fullyequipped physiotherapy room. It contains all the equipment expected of a modern department, ice, ultrasound, shortwave diathermy, cervical and lumbar traction, wall bars, wobble boards, bouncers and transcutaneous nerve stimulators. Clinic patients can be seen by the treatment room nurse if blood tests or an electrocardiogram (ECG) are indicated.

Address for correspondence:

J. Davison, MCSP

Department of Community Medicine

Bangour General Hospital

Broxburn

West Lothan

EH52 6LR
The secretarial and computing side of the clinic is undertaken by one of the personal secretaries in the health centre as part of her community medicine commitment. Originally the clinic's notes were maintained in specially designed manual records. In 1983 with the introduction of a microcomputer under the "Government Micros for GPs" scheme a Trivector Triton 4A was introduced into the health centre and all the clinic records were transferred onto the microcomputer. Later this was upgraded to an Apricot XEN. The sports medicine records were maintained on a separate part of the hard disk from the health centre patient records and both were protected by the use of passwords. A hard copy computer summary of each clinic consultation was also maintained.

Normally four patients attend by appointment, but urgent cases are always seen even if the clinic is fullybooked.

The clinic is run by a doctor (MPR) qualified and trained in community medicine. He has a five-session appointment in the local department as a Senior Medical Officer. He also works as a general practitioner (GP) at Howden Health Centre in Livingston where the clinic is based. The physiotherapist (JD) is a full-time Senior I community physiotherapist employed by Lothian Health Board and based in Livingston. She has been involved in the clinic for almost five years and treats all the clinic patients requiring physiotherapy in the health centre along with the other GP referrals. Both the doctor and physiotherapist have a special interest in sports medicine and regularly attend sports medicine courses.

Patients attending the clinic are assessed by the doctor and physiotherapist in a joint consultation. When one or other is unable to be present it operates on a single-handed basis. In the absence of the physiotherapist, arrangements are made for a colleague to provide treatment if appropriate. If the doctor is not present, the physiotherapist sees the patient as the Chartered Society of Physiotherapy revised rules of professional conduct permit this. Should a serious problem be presented when only the physiotherapist is present, medical advice can be sought from the patient's own GP or from the Accident and Emergency Department at the local hospital. In practice this has only occurred once.

The data held on computer were used to analyse the results of the first five years of the clinic's operation.

\section{RESULTS}

\section{Age/Sex Distribution}

The number of new patients seen during the five years of the study totalled 354 (Table I). The average age for men was 27 years and for women 23 years and there were three 
Age/sex distribution

\begin{tabular}{lrrr}
\hline Age & M & F & Total \\
\hline Over 40 & 33 & 3 & 36 \\
$30-39$ & 71 & 21 & 92 \\
$20-29$ & 88 & 26 & 114 \\
$10-19$ & 64 & 36 & 100 \\
Not known & 8 & 4 & 12 \\
Total & 264 & 90 & 354 \\
\hline
\end{tabular}

times as many males as females. The range of ages was very similar in both sexes 11-64 years in the case of men and 12-62 years for women. Men between the ages of 20 and 29, and women between the ages of 10-19 years consulted most frequently.

\section{Population}

The mini-clinic was set up to serve the town of Livingston which has a population of 41,000 . In practice, $66 \%$ (233) of patients attending the clinic resided in Livingston and the remainder (121) came from the surrounding small towns and villages.

\section{Sport}

Table II shows the types of sporting activities undertaken. Miscellaneous sports included such activities as Highland dancing, aerobics, horse riding and canoeing.

\section{TABLE ॥}

\begin{tabular}{lrrr}
\hline Sport & M & F & Total \\
\hline Running & 112 & 39 & 151 \\
Contact & 105 & 9 & 114 \\
Racquet & 22 & 11 & 33 \\
Miscellaneous & 25 & 31 & 56 \\
Total & 264 & 90 & 354 \\
\hline
\end{tabular}

\section{Anatomical Location of Problems}

Table III summarises the anatomical location of the problems seen at the clinic. These were classified according to the method used by Sperryn and Williams (Williams, 1971). Several patients consulted more than once with different problems or presented several problems at one consultation. About one-third of all problems seen at the clinic related to the knee joint, which has been a finding of other studies (Medhat et al, 1983; Davenport and Jackson, 1984). The lower limbs contributed well over three-quarters of all the injuries seen at the clinic from both sexes. Sports specific medical problems such as hypokalaemia represented only a small proportion $(3 \%)$ of consultations. Nevertheless, they are an important aspect of sports medicine as opposed to sports injuries and it $\cdot$ must be recognised that they may require an informed medical assessment for their diagnosis and management.

\section{Investigations}

In total 35 patients $(10 \%)$ had special investigations carried out. There were $26 \mathrm{X}$-ray requests, twelve blood tests, four urinalyses and three ECGs. In only one investigation was a

\begin{tabular}{lrrr}
\hline Problem & M & F & Total \\
\hline Neck/Trunk/Back & 27 & 8 & 35 \\
Shoulder & 16 & 6 & 22 \\
Arm/Elbow & 7 & 1 & 8 \\
Forearm/Wrist/Hand & 8 & 2 & 10 \\
Pelvis/Hip/Thigh & 37 & 9 & 46 \\
Knee & 99 & 37 & 136 \\
Calf & 47 & 14 & 61 \\
Ankle/Foot & 65 & 26 & 91 \\
Sport Specific Medical Problem & 12 & 3 & 15 \\
Total & 318 & 106 & 424 \\
\end{tabular}

serious abnormality discovered, namely a stress fracture of the tibia. However it is essential for a sports medicine clinic to have open access to laboratories and X-ray departments for the relatively rare occasions when doubt exists.

\section{Specialist Referral}

In setting up this pilot project, local hospital specialists were approached and gave their support to the experiment.

In the case of 36 patients $(10 \%)$ specialist advice was required. If a patient was referred to the clinic by his GP then in the event of a specialist opinion being required a direct referral was made and the GP informed. For patients who were referred to the clinic by their Coach, or who were self-referred, when a specialist opinion was indicated it was done through their own GP. It is recognised that this could be a sensitive area and this system seems to work well in practice.

The breakdown of specialist referrals was as follows: seven to an orthopaedic surgeon, five to a general surgeon with a special interest in sports medicine, two to a Casualty Department and one to an ear, nose and throat surgeon. All the patients referred for a specialist opinion are the subject of a separate study by the physiotherapist. Three athletes were referred directly to an interested chiropodist.

\section{Treatment}

Of the patients given treatment $70 \%$ had physiotherapy. The physiotherapy treatment used included:- ice, ultrasound, shortwave diathermy, frictions, wobble board, exercises, strappings, the teaching of appropriate warmups, cool-downs and stretching techniques, as well as advice on how to return to the chosen sport. Nineteen (6\%) patients were referred back to the clinic by the physiotherapist for reassessment. One hundred and ninetyfive $(79 \%)$ of the 248 patients referred for physiotherapy were discharged to resume the sport of their choice and therefore presumed injury-free. The group of $34(14 \%)$ for whom outcome of treatment is not known included those who were unable to attend for physiotherapy due to work commitments (seven), a few (fourteen) who just did not attend for treatment and a small group (thirteen) who failed to complete the course of treatment. The average number of attendances at physiotherapy per patient was seven, the range being two to sixteen.

Non-steroidal anti-inflammatory drugs were given to 19 people $(5 \%)$. Topical creams, mainly Benzydamine $\mathrm{HCL}$ Cream (Difflam-Riker) were occasionally used in conjunction with other treatments. Manipulation was used for the treatment of 22 patients $(6 \%)$. The remaining group 
of 65 patients $(18 \%)$ not given treatment as such was composed of the $36(10 \%)$ who were referred for a specialist opinion, the three $(1 \%)$ referred to the Chiropodist and 26 $(7 \%)$ who only required to be given advice or reassurance at the clinic consultation. Advice on prevention was a vital part of all treatment provided.

\section{Costing}

During the period of the pilot study no charge was made by the doctor or physiotherapist for their time, nor did the Health Board charge for accommodation or treatments. If the clinic were to be funded by the National Health Service the estimated costs are set out below:-

\section{Estimated Cost of Clinic}

Doctor

£20/session

(Based on Senior Medical Officer rate)

Physiotherapist

(Based on Whitley Council Senior I

excess hours rate)

Accommodation

Physiotherapy treatment

(Average 7 attendances per patient)

Clerical Support

Stationery/Sundries $\}$

f15/session

f11/session

£5/attendance

£8.25/session

\section{DISCUSSION}

It is unrealistic to believe that sports medicine clinics can be set up throughout the country based on local general hospitals. Acute injuries requiring hospital investigation and treatment are normally well catered for within the present structure of the National Health Service (NHS). It is not possible to meet all the needs of injured sportsmen in general practice. This means that a gap in care exists for the treatment of the less serious problem which prevents an individual participating in a sport of his choice. Our pilot study was an attempt to fill this gap in the care of sportsmen within the NHS. The clinic described here has made use of existing resources mainly provided through the local Department of Community Medicine.

It may be that such departments could facilitate the development of similar clinics elsewhere. The clinic ran without a break throughout the five years of the pilot project and continues to do so. However it did require the commitment of the physiotherapist and doctor. This is clearly the minimum number of staff required. Ideally extra staff would have been to our advantage, particularly during holidays or periods of high demand, such as the period leading up to a major marathon. In spite of the NHS cutbacks, the Department of Community Medicine continues to support the clinic. In our experience the amount of equipment required to operate this type of clinic is minimal and should never take the place of knowledge (Gamba, 1983). The main need is for time to assess the presenting problem, discuss treatment and advise on preventative measures. It is particularly important to understand the frustration felt by an incapacitated sportsman who does not want to lose fitness built up in a training programme.

It was uncertain initially how much of a demand the clinic would make on specialist services. In the event a second opinion was only required for $36(10 \%)$ of the patients (some six patients $(2 \%)$ were referred for a third opinion).

The consultants involved reported that they were happy to continue to support the clinic and that the number of occasions on which they were required to provide back-up for the clinic by giving a second opinion was not excessive and did not detract from their regular commitment to other NHS patients. The use of community resources has made it possible to run the clinic on a non-fee-paying basis. The organisation of sports medicine clinics will always have to take into account particular local circumstances. We recognise that when NHS facilities are not available it is reasonable to ask clubs and those attending the clinic to make a contribution to its expenses. There are various insurance schemes now available to cover the cost of the treatment of sports injuries.

\section{ACKNOWLEDGEMENTS}

The authors would like to thank Mrs. Anne King, the computer operator and Mrs. Mary Fisher and Mrs. Moira Wainwright for the production of this manuscript.

\section{References}

Brodie, D. A., 1983 "The University of Liverpool Sports Injuries Unit - A Practical Initiative". Physiotherapy 69: 277-278.

Burke, P., Buckley, N., McShane, D. and O'Connor, P., 1983 "Sports Injuries and the Casualty Department". Irish Medical Journal 76: 127-129.

Crompton, B. and Tubbs, N., 1977 "A Survey of Sports Injuries in Birmingham". Br. J. of Sports Med. 11: 12-15.

Davenport, M. P. and Jackson, E. A., 1984 "Use of Sports Medicine Clinic in a Family Practice Residency". J. of Family Practice 19: 225-228.

Gamba, L. A., 1983 "The University of Liverpool Sports Injuries Unit. The Physiotherapist's Viewpoint". Physiotherapy 69: 279.

Medhat, M. A. and Redford, J. B., 1983 "Knee injuries. Damage from Running and Related Sports". J. of Kansas Medical Society 7: 379-383.

Sperryn, P. N. and Williams, J. G. P., 1975 "Why Sports Injuries Clinics?". BMJ 3: 364-365.

Williams, J. G. P., 1971 "Aetiological Classification of Sports Injuries". Br. J. of Sports Med. 5: 228-230. 